\title{
3. \\ Ice ages and ecological transitions on temperate coasts
}

\author{
Michael H. Graham ${ }^{1, *}$, Paul K. Dayton ${ }^{2}$ and Jon M. Erlandson ${ }^{3}$ \\ ${ }^{1}$ Center for Population Biology, University of California, Davis, CA 95616, USA \\ ${ }^{2}$ Scripps Institution of Oceanography, University of California San Diego, La Jolla, CA 92093-0227, USA \\ ${ }^{3}$ Department of Anthropology, University of Oregon, 308 Condon Hall, Eugene, OR 97403-1218, USA
}

\begin{abstract}
Organisms face continual fluctuations in global climatic processes to which they must adapt or perish. Considering that many species are key habitat formers and energy producers, such responses to climate change can have significant population, community and even ecosystem consequences. Paleo-records of ecosystem responses to past environmental variability have proven invaluable for studying impacts of climate change on natural systems, yet such records are almost completely lacking for temperate benthic marine systems. Here, we bring together recent advances in paleoclimatology, coastal geomorphology, paleoceanography and archaeology for a well-studied region (the Southern California Bight, USA). We argue that there is now enough evidence to show that late-Quaternary sea-level rise over the past 18500 years has caused a large-scale ecological shift in this region from highly productive rocky reefs to less productive sandy shores. Our integrated approach has implications for other temperate coastlines and helps provide insight into the interactions between human culture, biological communities and their environments.
\end{abstract}

In terrestrial systems, ice ages result in significant habitat modification through climate change, direct structural transformation of the land because of glacier expansion and marine regression, and regulation of environmental conditions to which organisms respond physiologically through dispersal, growth and reproduction, affecting both their distribution and abundance [1-3]. As ice ages wane, the global climate warms, glaciers retreat, sea-level rises and organisms might emerge from refugia to colonize newly available habitat and adapt to the changing environment [4-6]. Developing a more detailed understanding of the general effects of ice ages on temperate coastal marine systems, however, has been challenging. Key habitat-forming and energy-producing species (e.g. kelp) rarely fossilize, and sea-level transgression has restricted the few existing temperate marine fossil beds to uplifted marine terraces. Thus, late-QUATERNARY (see Glossary) paleontological records are limited almost

\footnotetext{
* M.H. Graham will be at the following address from January 2003: Moss Landing Marine Laboratories, 8272 Moss Landing Road, Moss Landing, CA 95039, USA; e-mail: mgraham@mlml.calstate.edu.

Corresponding author: Michael H. Graham (mhgraham@ucdavis.edu).
}

entirely to mere glimpses of life during interglacial periods and high sea-level stands [7].

In regions where long archaeological records of coastal cultures exist, however, important data about the paleoecology of coastal ecosystems can often be found in the shell middens that mark the ancient campsites and villages of maritime peoples. When combined with information about sea-level histories, paleoclimatology, GEOMORPHOLOGY and paleoceanography, these data can be used to reconstruct relatively detailed histories of coastal ecosystem change. Such multi-disciplinary data sets have become available during the past decade for the Southern California Bight, a highly diverse and productive marine system, providing an unprecedented opportunity to study the dynamic relationship between ice ages and temperate coastal ecosystems since the last glacial maximum, 18500 years before present (BP). Although we focus on long-term ecological shifts that followed the most recent glacial recession, and only in one region, this approach offers new opportunities to gain insight into how global climate change can impact the structure and productivity of marine communities worldwide.

\section{Quaternary coasts of southern California}

A dramatic and obvious consequence of Quaternary ice ages is the continual fluctuation of global sea level, which affects the emergence and/or submergence of reefs, reef composition and coastline geomorphology. Cyclical changes in the eccentricity, obliquity and precession of the orbit of the Earth (Milankovitch cycles [8]) result in high amplitude oscillations of solar insolation [9], atmospheric and ocean temperatures $[10,11]$, and the formation and

\footnotetext{
Glossary

Cyclonic gyre: a counterclockwise circular current system.

Geomorphology: the scientific study of the landforms on the surface of the Earth, and of the processes that have fashioned them.

Holocene: the geological epoch spanning the past 10000 years; the Recent.

Pleistocene: the geological epoch from $\sim 1.8$ million until $\sim 10000$ years before present; the Ice Age.

Quaternary: the geological period comprising the Pleistocene and Holocene epochs; a sub-era of the Cenozoic.

Strike-slip fault system: a network of faults, each with lateral motion.

Subduction zone: where an oceanic plate is driven beneath another plate into

the mantle along a convergent boundary.

Upwelling: an upward movement of cold, nutrient-rich water caused by an offshore wind-driven current.
} 


\section{Box 1. Late-Quaternary sea-level change}

The geomorphic processes that shape coastlines are driven, in a large part, by variability in sea level, which can be measured at both global and regional scales.

\section{Geomorphic processes on a global scale}

Reconstructions of temporal variability in average global (eustatic) sea level rely primarily on estimates of the volume of water stored in or released from global ice sheets [a]. Because the oxygen isotopic ratio of seawater $\left({ }^{18} \mathrm{O}:{ }^{16} \mathrm{O}\right.$ or $\left.\mathrm{\partial}^{18} \mathrm{O}\right)$ is positively correlated with changes in icesheet volume [b], variability in $\partial^{18} \mathrm{O}$ from global ice and lake/marine sediment cores can be used as a first approximation of eustatic sea-level

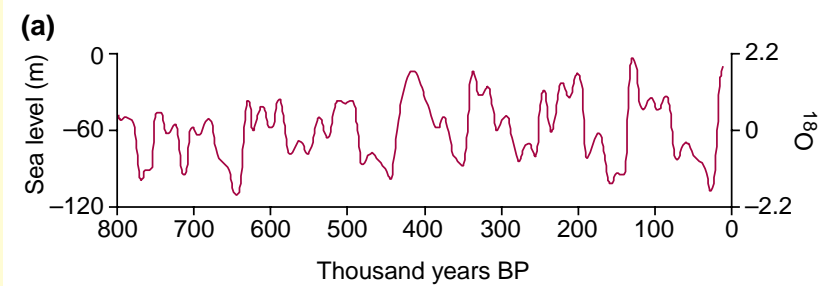

(b)

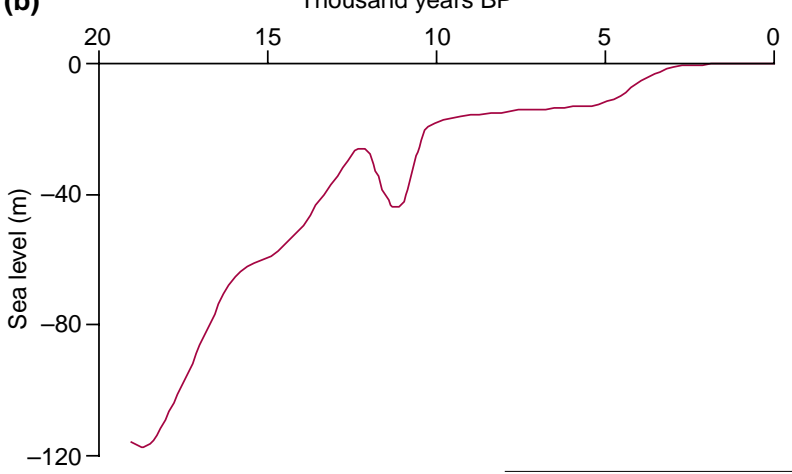

$\overline{T R E N D S ~ i n ~ E c o l o g y ~ \& ~ E v o l u t i o n ~}$

Fig. I. Global and regional seal-level change. (a) SPECMAP $\partial^{18} \mathrm{O}$ and eustatic sea-level curve. Data from Ref. [c]. (b) Sea-level curve for southern California (Santa Monica). Abbreviation: BP, before present. Reproduced, with permission, from Ref. [f].

destruction of polar ice sheets and continental glaciers [12]. During most of the Quaternary, global temperatures cycled continuously between cold glacial and warm interglacial extremes, with coastal habitats worldwide experiencing a cyclical pattern of rising and falling global temperatures and transgressing and regressing seas, demarcated by an extended period of steady sea levels during glacial or interglacial extremes (Box 1). In southern California, the minimum sea level during the last glacial maximum was $\sim 117 \mathrm{~m}$ below present and occurred $\sim 18500$ years BP, with an undulating rise to the onset of the current high sea level stand $\sim 6000$ years BP. Such dramatic changes in sea level had profound effects on southern California coastlines.

\section{Geomorphic processes}

The interaction between sea-level fluctuations and bathymetry (i.e. underwater topography) over broad spatial and temporal scales modifies reef distribution and coastline shape. Because the most productive temperate marine habitats are restricted to the photic zone [13] $(<30 \mathrm{~m}$ changes. The generally accepted eustatic sea-level curve for the last 800000 years comes from the SPECMAP data series [c,d] (Fig. la). In general, the SPECMAP eustatic curve exhibits peak temperatures of similar magnitude that occurred roughly every 100000 years, with a gradual 80 000-90 000 year build up to glacial conditions followed by rapid transition to interglacials within 10 000-20000 years or less.

\section{Geomorphic processes on a regional scale}

The SPECMAP eustatic curve provides a good estimate of average global sea-level changes. Yet, sea-level curves developed for specific regions, usually through radiocarbon dating of sediment deposits and seismic stratigraphy, can deviate strongly from this curve [e]. This is due to a variety of complex geological processes (e.g. tectonics, seismic uplift, isostatic rebound or subsidence) that modify the vertical motion of coastal landforms relative to the global average sea level [a]. Such regionally (isostatic) derived sea-level curves provide a more detailed view of late-Quaternary sea-level change that is relevant to the reconstruction of coastal habitats. For example, in southern California, sea-level rise since the last glacial maximum was rapid, $\sim 1 \mathrm{~m}^{\text {century }}{ }^{-1}$, until $\sim 6000$ years BP when transgression slowed to $\sim 0.01 \mathrm{~m}^{\text {century }}{ }^{-1}$ [f] (Fig. lb). This post-glacial transgression (termed the Flandrian transgression) appears to have occurred in two steps separated by a warm pause correlated with the Bolling/Allerod Interstadial [15 200-13 000 years before present (BP)] and the Younger Dryas cooling (13 000-11 100 years BP).

\section{References}

a Lambeck, K. and Chappell, J. (2001) Sea-level change through the last glacial cycle. Science 292, 679-686

b Waelbroeck, C. et al. (2002) Sea-level and deep water temperature changes derived from benthic foraminifera isotopic records. Quat. Sci. Rev. 21, 295-305

c Imbrie, J. et al. (1984) The orbital theory of Pleistocene climate: support from a revised chronology of the marine $\partial^{18} \mathrm{O}$ record. In Milankovitch and Climate (Berger, A et al., eds), pp. 269-305, Reidel Publishing Company

d Martinson, D.G. et al. (1987) Age dating and the orbital theory of the ice ages: development of a high-resolution 0-300 000 year chronostratigraphy. Quat. Res. 27, 1-29

e Curray, J.R. (1961) Late Quaternary sea level: a discussion. Geol. Soc. Am. Bull. 72, 1707-1712

f Nardin, T.R. et al. (1981) Holocene sea-level curves for Santa Monica shelf, California continental borderland. Science 213, 331-333

depth), spatial variability in coastal bathymetry will define the distribution of biologically productive reefs. Unlike nearby regions to the north and south, the bathymetry of the Southern California Bight is highly variable because of the geologically recent transformation of a previously active SUBDUCTION ZONE into a STRIKESLIP FAULT SYSTEM [14]. This transformation was driven by the collision of an eastward migrating mid-ocean spreading center with the once-active subduction zone, beginning $\sim 40$ million years BP. Subsequent uplift, subsidence, rotation, compression and extension because of faulting and tectonics resulted in a mosaic of basins, islands and offshore banks embedded within a widened region of the continental shelf. Within this region, the size, shape and location of reefs varied as sea level changed, as did the horizontal distances separating reefs among island and mainland sites (Fig. 1).

The dynamic geomorphology of the southern California coastline is also regulated by interrelated changes in sea level, erosion and the accumulation and deposition of sediments along coastal margins [15] (Fig. 2). During 


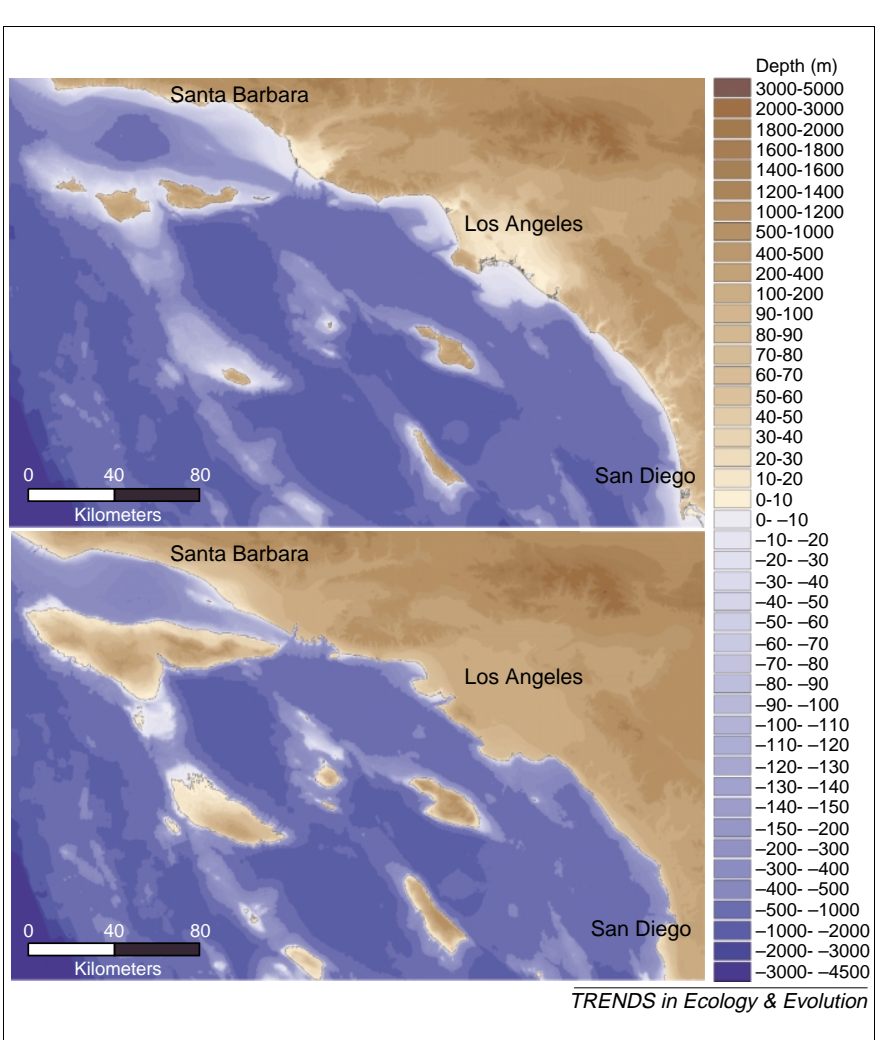

Fig. 1. Bathymetry of the Southern California Bight during (a) the current interstadial (high sea level) and (b) the last glacial maximum (low sea level, 18500 years before present).

periods of falling sea level, changes in stream base level and increased velocity of runoff waters cut deep coastal canyons, and coarse sediments (cobbles and boulders) are deposited along the coastline, creating a dominance of cobbled, rocky shore with interstitial sand [16]. Under postglacial conditions of rapidly rising sea levels, the dominant geomorphic process shifts from erosion to deposition, with finer sediments deposited in bays or estuaries formed at the mouths of newly flooded coastal canyons rather than along the coastline. Longshore currents sweep the interstitial sands into submarine canyons, enhancing the dominance of cobbled rocky shores, as evidenced by extensive subtidal HOLOCENE cobble and boulder deposits throughout the Southern California Bight [17]. As sea-level rise slows, these estuarine embayments fill with sediment and, given an extended high sea-level stand, marshes, meandering coastal streams, mud flats and extensive beaches are ultimately formed, as currently occur along much of the mainland coast of the Southern California Bight.

\section{Oceanographic processes}

In addition to sea-level-driven fluctuations in reef distribution and substrate composition (i.e. rocky versus sandy shorelines), Quaternary glacial-interglacial cycles have driven long-term changes in oceanographic conditions and the availability of limiting resources to primary producers. Currently, the dominant hydrographic regime of the Southern California Bight is characterized by a semipermanent CYCLONIC GYRE, incorporating water from the cool southward-flowing California Current, with warmer countercurrent waters intruding from the southeast [18]. Oceanographic productivity within the region is linked to longshore transport of nutrients from an UPWELLING region near Point Conception and other promontories, and onset of upwelling events generally corresponds to periods of strong spring equatorward winds and strong flow of the California Current. As such, sea-surface temperatures within nearshore regions of the Southern California Bight generally range from 12 to $20^{\circ} \mathrm{C}$, corresponding with in situ nitrate concentrations of 15$0 \mu \mathrm{M}$, respectively, [19].

However, hydrographic conditions were very different in the Southern California Bight during the last glacial maximum. With lower sea levels, all of the Channel Islands increased in area, the northern Channel Islands consolidated, and many currently submerged offshore banks became islands with extensive shoals [20] (Fig. 1). The Santa Barbara and Anacapa Channels then combined to form a narrow, sheltered body with restricted circulation, although the Santa Barbara Basin appeared to be better ventilated than it is at present [21]. Average seasurface temperatures within the Southern California
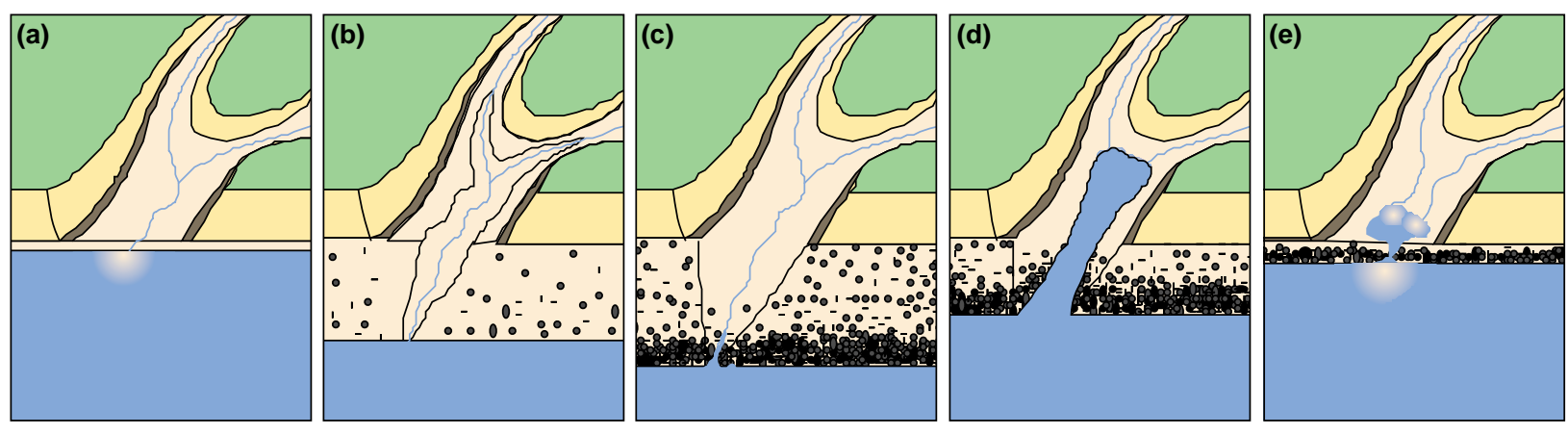

$\overline{T R E N D S ~ i n ~ E c o l o g y ~ \& ~ E v o l u t i o n ~}$

Fig. 2. Sea level-driven transitions between rocky-cobbled and sandy shores. (a) High sea-level stands (interglacials): coastal canyons are filled with sediment (estuaries with sediment deposition (river plumes) occurring along the open coast. (b) Falling sea level (marine regression): velocity of runoff waters and grain size of sediments increase with cobbles deposited downstream along the broadening coastline. (c) Low sea-level stands (glacials): extensive cobbled shore and deep coastal canyons. (d) Rapidly rising sea level (early marine transgression): runoff velocities decrease and sediment deposition moves inland, starving coastline of sand. (e) Slowly rising sea level (late marine transgression): sea-level stabilization increases coastal erosion and sand is again deposited along the open coast. Modified, with permission, from Ref. [15]. 
Bight also dropped to $7-8{ }^{\circ} \mathrm{C}$ [21,22]. Although new isotopic data from sediment cores from the Southern California Bight suggest that there might have been a weakening in the California Current between 15000 and $20000 \mathrm{BP}$ [23], stronger winds blowing across the larger land masses apparently resulted in greater localized upwelling than is seen at present [24,25]. Increased upwelling intensity during the last glacial maximum has also been observed for other upwelling regions around the world [26]. Thus, we believe that the Southern California Bight would have had relatively high nutrient levels.

\section{Ecological shifts since the last glacial maximum}

We view the now sand-dominated coastlines of the Southern California Bight, characteristic of the current high sea-level stand and so important to contemporary perspectives of the ecology of coastal systems, as ephemeral over geological and evolutionary timescales. In fact, these warm sandy temperate coasts appear to have developed only over the past 4000-6000 years [15], and we reason that most of the late PLEISTOCENE and early Holocene was characterized by extensive cold, rocky, cobbled shores, punctuated by estuarine embayments. Furthermore, these coasts appear to have experienced essentially continuous fluctuations in reef distribution and size, shifts from cold to warm hydrographic conditions, and cycling between sandy and rocky shores with each glacialinterglacial cycle.

The transition between sandy and rocky habitats is a key to reconstructing shifts in marine ecosystems, because sand and rock substrata support very different benthic communities. The relatively unstable sandy habitats are characterized by microalgae and robust infaunal and epifaunal macroinvertebrates that have various adaptations for living on and within a dynamic substratum that is heavily influenced by water motion. In addition to the highly unstable substrata, intertidal sand areas are exposed to periodic drying and sometimes considerable lateral and vertical transport [26]. Sand invertebrate assemblages are characterized by scattered individuals that rarely reach high enough densities to stabilize the sand-exceptions include assemblages of bivalves, sand dollars, sea pens and polychaetes that episodically occur in water deeper than $10 \mathrm{~m}$ [27]. Rocky habitats, by contrast, are characterized by relatively large macroalgae, usually various species of brown algae that tend to be highly productive and offer many types of food and structure to the nearshore ecosystem [28]. These biological structures influence and moderate the physical environment and fuel diverse food webs [29]. Thus, sandy and rocky habitats have enormous differences in productivity and biodiversity.

\section{Ecology of ice-age kelp forests}

The ecological perspective emerging from such reconstructions of the late Pleistocene environment is that of an ideal habitat for kelp-based rocky shore ecosystems. The environmental parameters most important to kelp-based ecosystems are hard substrata within 25-40 m depth and cool nutrient-rich waters [30]. Modeling the paleogeography of the Channel Islands in southern California over the past 18500 years suggests that an increased area of available substrate within the photic zone during the late Pleistocene would have provided for large and extensive subtidal kelp forests (M.H. Graham, unpublished).

We suspect that these ice-age kelp forests were inhabited by the extensive populations of large fish (e.g. giant black sea bass Stereolepis gigas, ling cod Ophiodon elongatus, many species of rockfish Sebastes spp., cabezon Scorpaenichthys marmoratus and sheephead Semicossyphus pulcher) and invertebrates that were observed in southern California kelp forests before the onset of extensive fishing [31]. Certainly, the expansive algaldominated rocky habitat would have supported large populations of sea urchins, abalones and other gastropods, mussels, and other bivalves associated with rocky habitats. This also would have been an ideal habitat for the sea otter Enhydra lutris, hunted to extinction locally during the early $1800 \mathrm{~s}$. Sea otters probably foraged much as they do now off the coast of central California, with their shellfish prey being most abundant in refugia beneath ledges, cracks and crevices, and at depths below the diving limits of otters [32,33].

Furthermore, besides providing habitat and energy for associated flora and fauna, coastal kelp populations export significant amounts of detritus to other nearshore oligotrophic habitats (e.g. shallow and deep water basins, and coastal terrestrial ecosystems) (Box 2). If our geological and oceanographic reconstructions hold true, then, during the height of the last glacial, increased upwelling and the emergence of rocky substrate would have supported rich intertidal habitats that might have been similar to those presently found north of the Southern California Bight [34]. By the end of the Pleistocene, archaeological data from the Channel Islands suggest that rocky intertidal communities dominated by large mussels, abalones, turban snails and other invertebrates were abundant and highly productive $[35,36]$.

Finally, that the abundance and productivity of rocky benthic communities in the Southern California Bight might have decreased sharply since the last glacial maximum, in conjunction with marked habitat fragmentation, is in striking contrast to the current perspective of post-ice-age ecosystem shifts on land. Although exceptions exist, the general trend in terrestrial systems has been range expansion, population coalescence and increased terrestrial productivity, with the shift from glacial to interglacial conditions [37,38]. As such, the response of temperate marine and terrestrial systems to glacialinterglacial cycles appears to be out of phase.

\section{Environmental change and human ecology}

A wealth of archaeological data from southern California coastal sites offers a unique and independent data set with which to observe and validate sea-level-driven shifts in nearshore ecosystems. Native Americans first arrived in the Southern California Bight region at least 12 00013000 years BP, at which time they had already colonized the northern Channel Islands [39,40]. The changes in the coastal environment that we have suggested would have modified the marine resources available to these people. Throughout the past 12000 years, rocky shore and 
Box 2. Kelp subsidies and cross-system exchanges

Given the fluid nature of the marine environment, primary production generated in coastal kelp forests can be exported to and utilized by other marine and non-marine systems.

\section{Soft sediment subsidies}

Giant kelp Macrocystis pyrifera is the main exporter of seaweed biomass in the Southern California Bight, contributing between 60 and $99 \%$ of beach-cast phytodetritus [a]. Detached giant kelp canopies (rafts) can be dispersed over long distances by rafting [b]. When rafts lose their buoyancy, they wash into shallow nearshore habitats [c] and deep offshore basins [d], where they help to fuel secondary productivity of soft-sediment systems (Fig. I). We suggest that kelp subsidies to softsediment systems in the Southern California Bight have decreased since the last glacial maximum because of decreases in kelp distribution and increases in the size of offshore basins.

\section{Intertidal and terrestrial subsidies}

Kelp detritus can also enter nearby intertidal food webs as fine particles captured by filter feeders (e.g. mussels [e] or clams [f]) or large pieces grabbed by limpets [g]. The importance of such subsidies to intertidal systems will depend on both the size and productivity of offshore kelp populations and the linear extent of the rocky intertidal (e.g. the perimeter of offshore islands). Furthermore, the inherently low productivity of terrestrial ecosystems on arid islands can also be significantly enhanced by the flow of energy from highly productive surrounding waters $[\mathrm{h}]$. It has been shown that, during dry years, marine subsidies in the form of feces and detritus have the greatest impact on islands with large shoreline (perimeter):area ratios (i.e. small islands, Fig. II), but that such subsidies lessen during rainy years, when high precipitation drives much higher levels of terrestrial productivity. In the Southern California Bight, shorelines of the relatively less productive Channel Islands have high accumulations of marine bird and mammal feces and are seasonally loaded with large amounts of marine detritus, dominated by beach-cast giant kelp [a]. Unlike soft-sediment systems, however, it is unclear to us whether kelp subsidies to intertidal and
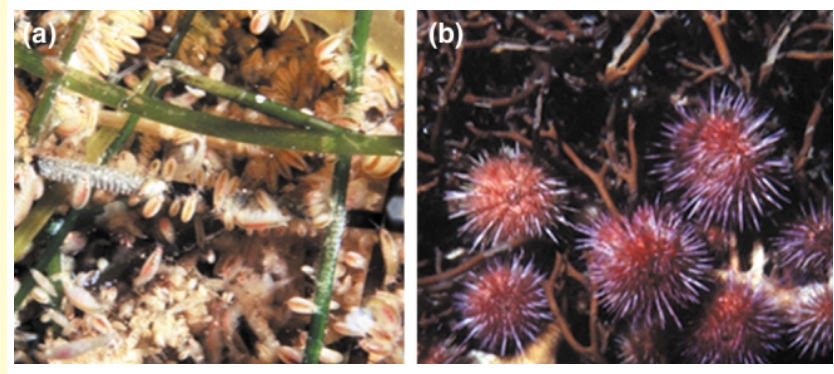

Fig. I. Giant kelp-derived phytodetritus, including (a) crustacean detritivores (mainly leptostracans) and (b) sea urchins, on sandy plains in the Southern California Bight. Photos, reproduced with permission, from E. Vetter.

kelp-bed habitats provided abundant food supplies, but their abundance and productivity undoubtedly fluctuated through space and time [41]. Archaeological data suggest that, as mainland coastlines evolved from predominantly rocky to predominantly sandy habitats $(\sim 4000-6000$ years $\mathrm{BP}$ ), the composition of the coastal fauna and flora shifted from a diverse assemblage of edible epifaunal invertebrates (mussels, abalone, oysters, etc.) and seaweeds, to an infaunal assemblage that, except for clams, produced much less food that was useful to people $[41,42]$. Although considerable variation is evident among the ways of life of Native American peoples of coastal southern California, general changes in their food habits appear to

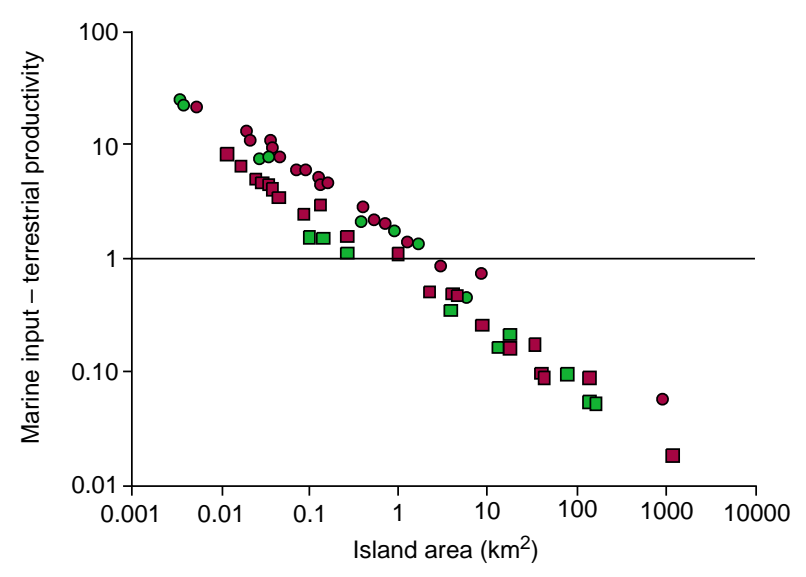

Fig. II. Importance of marine subsidies versus island size and precipitation. The horizontal line indicates a distinction between systems driven primarily by marine $(>1)$ versus terrestrial $(<1)$ inputs. Precipitation: red circles, $59 \mathrm{~mm} \mathrm{yr}^{-1}$; green circles, $75 \mathrm{~mm} \mathrm{yr}^{-1}$; red squares, $125 \mathrm{~mm} \mathrm{yr}^{-1}$; green squares, $150 \mathrm{~mm} \mathrm{yr}^{-1}$. Modified, with permission, from Ref. [h].

terrestrial systems in the Southern California Bight have increased or decreased since the last glacial maximum.

\section{References}

a Zobell, C.E. (1971) Drift seaweeds on San Diego County beaches. Nova Hedwigia 32, 269-314

b Hobday, A.J. (2000) Abundance and dispersal of drifting kelp Macrocystis pyrifera rafts in the Southern California Bight. Mar. Ecol. Prog. Ser. 195, 101-116

c Vetter, E.W. (1995) Detritus-based patches of high secondary production in the nearshore benthos. Mar. Ecol. Prog. Ser. 120, 251-262

d Harrold, C. et al. (1998) Organic enrichment of submarine-canyon and continental shelf benthic communities by macroalgal drift imported from nearshore kelp forests. Limnol. Oceanogr. 43, 669-678

e Duggins, D.O. et al. (1989) Magnification of secondary production by kelp detritus in coastal marine ecosystems. Science 245, 170-173

f Soares, A.G. et al. (1997) Carbon and nitrogen exchange between sandy beach clams (Donax serra) and kelp beds in the Benguela coastal upwelling region. Mar. Biol. 127, 657-664

g Bustamante, R.H. et al. (1995) Maintenance of an exceptional intertidal grazer biomass in South Africa: subsidy by subtidal kelps. Ecology 76, 2314-2329

h Polis, G.A. and Hurd, S.D. (1996) Linking marine and terrestrial food webs: allochthonous input from the ocean supports high secondary productivity on small islands and coastal land communities. Am. Nat. 147, 396-423

have tracked sea-level-induced changes in coastal habitats and associated biotic communities (Box 3). At the same time, through predation on key functional species, such as sea otters, predatory fish and sea urchins, these maritime peoples might have actively shaped the ecosystems that they were part of.

Native American use of the nearshore environment, however, was not limited to biotic resources. The cobble beaches that dominated the early coastline provided ample materials for making grinding tools widely used for food processing. In fact, ground stone cobble tools [metates (querns) and manos (mullers)] are so abundant in early coastal sites that most mainland sites dating between 


\section{Box 3. The human connection}

Coastal cultures have relied regularly on nearshore marine resources in the Southern California Bight for $>13000$ years before present (BP), although striking differences exist between the mainland and offshore islands.

\section{Mainland sites}

Numerous mainland archaeological sites dated between $\sim 10000$ and 6000 years BP indicate that intertidal foraging was a foundation of early coastal economies in the Southern California Bight for millennia [a,b]. Shellfish assemblages found around paleo-estuary sites are dominated by estuarine bivalves (e.g. Chione, Saxidomus and Ostrea), yet some of the earliest sites are rich in California mussels Mytilus californianus harvested from the rocky intertidal [a]. By the middle Holocene ( $\sim 6500-$ 4000 years BP), many of the smaller mainland estuaries silted in and disappeared as productive habitats for human foraging [c], although some larger estuaries continued to exist until the late Holocene and even historic times.

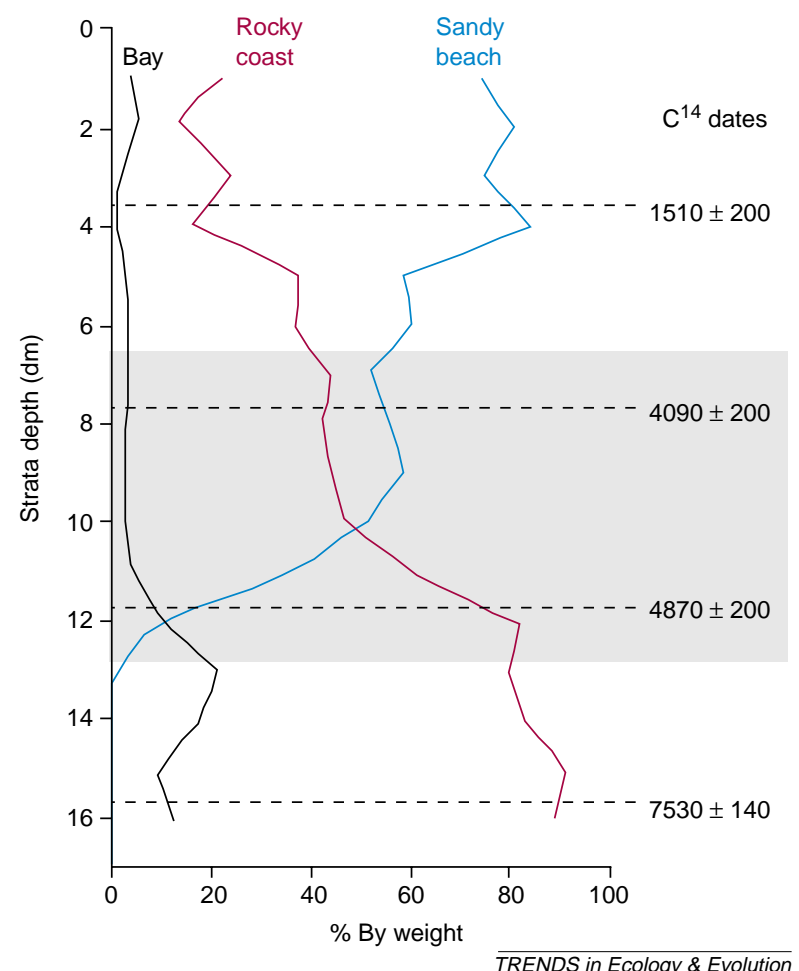

Fig. I. Temporal fluctuations in bay, rocky coast and sandy beach molluscan remains from an open coast shell midden on the California mainland. Carbon dates $\left(\mathrm{C}^{14}\right)$ for various strata are given on the right. Gray box indicates proposed period of sea-level-driven shift from rocky to sandy habitats. Modified, with permission, from Ref. [e].
Around the time of our proposed transitioned between rocky and sandy coasts ( $\sim 4000-6000$ years BP), shellfish assemblages from many coastal localities showed a marked shift towards taxa typical of waveswept sandy beaches (e.g. Tivela and Donax) [c,d] (Fig. I). Along with human population growth, this shift appears to have contributed to a greater emphasis on terrestrial resources (e.g. acorns) in some areas and to intensified kelp bed and pelagic fishing in others [e].

\section{Island sites}

On the California Channel Islands, low sediment input to the coast probably limited sea-level-driven shifts from rocky to sandy habitats. Here, terrestrial ecosystems are relatively impoverished and humans appear to have depended primarily on marine resources throughout the 12000 years of human occupation. The high diversity of shells (mussels, abalones, turban snails and sea urchins) and animal bones (fish, sea otters, pinnipeds and sea birds) show that these early human occupants were adept at harvesting rocky intertidal, kelp bed and other nearshore resources. In stratified and well-preserved shell middens on San Miguel Island, where the record of human occupation begins $\sim 12000$ years BP and spans much of the Holocene, a suite of rocky shore shellfish, nearshore and kelp forest fish, and sea mammals are present throughout the sequence $[f-h]$, supporting the notion of a continuous presence of rocky habitat. Although Native peoples clearly impacted Channel Island kelp bed and rocky intertidal communities, archaeological data suggest that such impacts led to very few extinctions and that general exploitation patterns were sustained over millennia - in stark contrast to the devastating exploitation that followed European colonization.

\section{References}

a Erlandson, J.M. (1994) Early Hunter-Gatherers of the California Coast, Plenum

b Jones, T.L. (1991) Marine resource value and the priority of coastal settlement: a California perspective. Am. Antiq. 56, 419-443

c (1997) The Archaeology of the California Coast during the Middle Holocene (Erlandson, J.M., Glassow, M.A. eds), UCLA Institute of Archaeology

d Glassow, M.A. and Wilcoxon, L. (1988) Coastal adaptations near Point Conception, California, with particular regard for shellfish exploitation. Am. Antiq. 53, 36-51

e Masters, P.M. and Gallegos, D.R. (1997) Environmental change and coastal adaptations in San Diego County during the Middle Holocene. The Archaeology of the California Coast during the Middle Holocene (Erlandson, J.M., Glassow, M.A. eds), pp. 11-21, UCLA Institute of Archaeology

f Erlandson, J.M. et al. (1996) An archaeological and paleontological chronology for Daisy Cave (CA-SMI-261), San Miguel Island, California. Radiocarbon 38, 355-373

g Vellanoweth, R.L. et al. (2000) Middle and Late Holocene maritime adaptations on northeastern San Miguel Island, California. In The Fifth California Islands Symposium (Brown, D.K. et al., eds), pp. 607-614, Santa Barbara Museum of Natural History

h Rick, T.C. et al. (2001) Paleocoastal marine fishing on the Pacific Coast of the Americas: perspectives from Daisy Cave, California. Am. Antiq. 66, 595-614

and to the development of specialized mortar- and pestlemanufacturing villages on the northern Channel Islands, where cobbles were still available [43].

\section{Prospects}

Until relatively recently, much of the coastal marine environment of southern California was fundamentally different to what it is today. The coastal zone fluctuated between long periods of rocky kelp-forest-dominated habitats and relatively brief periods of sandy infaunal shift from mortars to pottery in the San Diego area [42] 
dominance, at an approximate frequency of 100000 years, driven by climate and sea-level change. This different perspective is fundamental to our understanding of the ecological and evolutionary processes that shape nearshore ecosystems and their subsequent impact on resource utilization by coastal people. What remains to be seen is whether the transition between rocky and sandy habitats, presented here, occurred for other temperate coastlines around the world. If it did, can our integrated approach be used to detect such changes? We think so. Multidisciplinary data sets (e.g. climatic, oceanographic, geological and paleontological) are being assembled for a variety of temperate marine ecosystems worldwide, many of which are in regions were detailed archaeological data for maritime cultures are also available (e.g. Australia, South Africa, Chile and Japan). Synthetic analyses of such data will expose novel and exciting questions for investigation. For example, will anthropogenic climate change (e.g. global warming-induced sea-level rise and decreased sediment transport because of human water utilization) hasten or slow transitions between rocky and sandy habitats, and thus impact marine productivity and fisheries yield? Can predictions based on geological and archaeological records help avert or lessen future impacts? Did fluctuations between the use of marine versus terrestrial resources have a significant effect on the evolution of nonhuman biological communities during the Holocene?

Although it will take time to answer such questions, it is important that we begin to better appreciate the strong impacts that long-term geological variability and human intervention have had on the evolution of interactions between human culture, biological communities and their environments.

\section{Acknowledgements}

We thank Lara Ferry-Graham, Rick Grosberg, Brad Werner, Jeremy Jackson, Jerry Winterer, Doug Inman, Pat Masters, Jay Stachowicz, Dan Reed, Geerat Vermeij and an anonymous reviewer for discussion and comments. This work was supported by a University of California Faculty Fellowship to M.H.G.

\section{References}

1 COHMAP Project Members, (1988) Climatic changes of the last 18000 years: observations and model simulations. Science 241, 1043-1052

2 Prentice, I.C. et al. (1993) Modeling global vegetation patterns and terrestrial carbon storage at the last glacial maximum. Global Ecol. Biogeogr. Lett. 3, 67-76

3 Jackson, S.T. and Overbeck, J.T. (2000) Responses of plant populations and communities to environmental changes of the late Quaternary. Paleobiology 26, 194-220

4 Bennett, K.D. (1990) Milankovitch cycles and their effects on species in ecological and evolutionary time. Paleobiology 16, 11-21

5 Hewitt, G. (2000) The genetic legacy of the Quaternary ice ages. Nature 405, 907-913

6 Davis, M.B. and Shaw, R.G. (2001) Range shifts and adaptive responses to Quaternary climate shifts. Science 292, 673-679

7 Lindberg, D.R. and Lipps, J.H. (1996) Reading the chronicle of Quaternary temperate rocky shore faunas. In Evolutionary Paleobiology (Jablonski, D., ed.), pp. 161-182

8 Berger, A. (1988) Milankovitch theory and climate. Rev. Geophys. 26 , 624-657

9 Berger, A. and Loutre, M.F. (1992) Insolation values for the climate of the last 10 million years. Quat. Sci. Rev. 10, 297-318

10 Shackleton, N.J. and Opdyke, N.D. (1973) Oxygen isotope and palaeomagnetic stratigraphy of equatorial Pacific core V28-238: oxygen isotope temperatures and ice volumes on a 105 year and 106 year scale. Quat. Res. 3, 39-55

11 Lea, D.W. et al. (2000) Climate impact of late Quaternary equatorial Pacific sea surface temperature variations. Science 289, 1719-1724

12 Peltier, W.R. (1994) Ice age paleotopography. Science 265, 195-201

13 Mann, K.H. (1973) Seaweeds: their productivity and strategy for growth. Science 182, 975-981

14 Legg, M.R. (1991) Developments in understanding the tectonic evolution of the California Continental Borderland. In Shoreline to Abyss (Osborne, R.H., ed.), pp. 291-312, Society for Sedimentary Geology

15 Inman, D.L. (1983) Application of coastal dynamics to the reconstruction of palaeocoastlines in the vicinity of La Jolla. Quaternary Coastlines and Marine Archaeology (Masters, P.M., Fleming, N.C. eds), pp. 1-49, Academic Press

16 Emery, K.O. (1960) The Sea off Southern California, Wiley

17 Emery, K.O. et al. (1952) Submarine geology off San Diego, California. J. Geol. 60, 511-548

18 Hickey, B.M. (1992) Circulation over the Santa Monica-San Pedro basin and shelf. Prog. Oceanogr. 30, 37-115

19 Zimmerman, R.C. and Robertson, D.L. (1985) Effects of El Niño on local hydrography and growth of the giant kelp, Macrocystis pyrifera, at Santa Catalina Island, California. Limnol. Oceanogr. 30, 1298-1302

20 Johnson, D.L. (1983) The California continental borderland: landbridges, watergaps and biotic dispersals. Quaternary Coastlines and Marine Archaeology (Masters, P.M., Fleming, N.C. eds), pp. 481-527, Academic Press

21 Kennett, J.P. and Ingram, B.L. (1995) Paleoclmatic evolution of Santa Barbara Basin during the last 20 k.y.: marine evidence from Hole 893A. Proc. Ocean Drilling Prog. Sci. Res. (Part 2) 146, 309-325

22 Kennett, J.P. and Venz, K. (1995) Late Quaternary climatically related planktonic foraminiferal assemblage changes: Hole 893A, Santa Barbara Basin, California. Proc. Ocean Drilling Prog. Sci. Res. (Part 2) $146,281-293$

23 Herbert, T.D. et al. (2001) Collapse of the California Current during glacial maxima linked to climate change on land. Science 293, 71-76

24 Gorsline, D.S. and Prensky, S.E. (1975) Paleoclimatic inferences for late Pleistocene and Holocene from California Continental Borderland basin sediments. Quaternary Studies (Suggate, R.P., Cresswell, M.M. eds), pp. 147-154, Royal Society of New Zealand

25 Freudenthal, T. et al. (2002) Upwelling intensity and filament activity off Morocco during the last 250000 years. Deep-Sea Res. II 49, $3655-3674$

26 Brown, A.C. and McLachlan, A. (1990) Ecology of Sandy Shores, Elsevier

27 Dexter, D.M. (1992) Sandy beach community structure: the role of exposure and latitude. J. Biogeogr. 19, 59-66

28 Paine, R.T. (2002) Trophic control of production in a rocky intertidal community. Science $296,736-739$

29 Sala, E. and Graham, M.H. (2002) Community-wide distribution of predator-prey interaction strength in kelp forests. Proc. Natl Acad. Sci. USA 99, 3678-3683

30 Dayton, P.K. (1985) Ecology of kelp communities. Annu. Rev. Ecol. Syst. 16, 215-245

31 Dayton, P.K. et al. (1998) Sliding baselines, ghosts, and reduced expectations in kelp forest communities. Ecol. Appl. 8, 309-322

32 (1988) The Community Ecology of Sea Otters, Ecological Studies: Analysis and Synthesis (Van Blaricom, G.R., Estes, J.A. eds), Springer

33 Riedman, M.L. and Estes, J.A. (1990) The Sea Otter (Enhydra lutris): Behavior Ecology, and Natural History, US Fish and Wildlife Service

34 Foster, M.S. et al. (1991) Open coast intertidal and shallow subtidal ecosystems of the northeast Pacific. Ecosystems of the World: Intertidal and Littoral Ecosystems (Mathieson, A.C., Nienhuis, P.H., et al. eds), pp. 235-272, Elsevier

35 Erlandson, J.M. et al. (1999) Maritime subsistence at a 9300-year-old shell midden on Santa Rosa Island, California. J. Field Archaeol. 26, $255-265$

36 Erlandson, J.M. and Rick, T.C. (2002) Late Holocene cultural developments along the Santa Barbara Coast. Catalysts to Complexity: Late Holocene Societies of the California Coast (Erlandson, J.M., Jones, T.L. eds), UCLA Institute of Archaeology, in press 
37 Bennett, K.J. (1997) Evolution and Ecology: The Pace of Life, Cambridge University Press

38 Williams, D. et al. (1998) Quaternary Environments, Arnold

39 Erlandson, J.M. and Moss, M.L. (1996) The Pleistocene-Holocene transition along the Pacific Coast of North America. In Humans at the End of the Ice Age: The Archaeology of the Pleistocene-Holocene Transition (Straus, B.V. et al., eds), pp. 277-301, Plenum

40 Johnson, J.R. et al. (2000) Arlington Springs Revisited. In The Fifth California Islands Symposium (Brown, D.K. et al., eds), pp. 541-545, Santa Barbara Museum of Natural History

41 Masters, P.M. (1983) Detection and assessment of prehistoric artifact sites off the coast of southern California. Quaternary Coastlines and Marine Archaeology (Masters, P.M., Fleming, N.C. eds), pp. 189-213, Academic Press

42 Masters, P.M. (1985) California coastal evolution and the La Jollans. Oceanus 28, 27-34

43 Kennett, D. and Conlee, C. (2002) Emergence of Late Holocene sociopolitical complexity on Santa Rosa and San Miguel Islands. Catalysts to Complexity: Late Holocene Societies of the California Coast (Erlandson, J.M., Jones, T.L. eds), UCLA Institute of Archaeology, in press

the quarterly magazine for the history and philosophy of science

Online access to Endeavour is FREE to BioMedNet subscribers, providing you with a collection of beautifully illustrated articles on the history of science, book reviews and editorial comment.

\section{featuring}

Gardens of paradise by Staffan Müller-Wille

Crookes, carbolic and cattle plague by William $\mathrm{H}$. Brock

Benjamin West's portrait of Joseph Banks by Patricia Fara

British cell theory on the eve of genetics by Marsh L. Richmond

Humphrey Davy: science and social mobility by David M. Knight

Replanting Eden: John Evelyn and his gardens by Sandra Sherman

Biochemistry comes of age: a century of endeavour by Keith L. Manchester

The ethics of vaccine usage in society: lessons from the past by Hervé Bazin

Genetics, eugenics and the medicalization of social behaviour by Garland $\mathrm{E}$. Allen

Artists as scientists: nature and realism in early-modern Europe by Pamela $\mathrm{H}$. Smith

Elegant hypothesis and inelegant fact in developmental biology by Nicholas A.M. Monk

Exotic abortifacients: the global politics of plants in the 18th century by Londa Shiebinger

Designing nature reserves: adapting ecology to real-world problems by Sharon Kingsland

Ramón y Cajal: a century after the publication of his masterpiece by Pedro J. Andres-Barquin The understanding of monsters at the Royal Society in the 18th century by Palmira F. da Costa

$$
\text { and much, much more... }
$$

Locate Endeavour in the extensive BioMedNet Reviews collection.

Log on to http://reviews.bmn.com, hit the 'Browse Journals' tab and scroll down to Endeavour BOOKMARK TODAY 